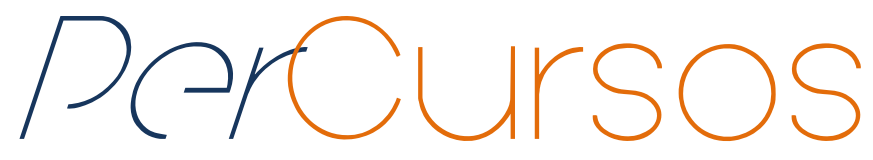

\title{
A multidimensionalidade da imigração boliviana em São Paulo: perspectivas das cadeias globais como estratégia de análise
}

\begin{abstract}
Resumo
O presente artigo pretende analisar diversas dimensões da imigração boliviana e sua inserção nas oficinas clandestinas de costura em São Paulo, a partir da perspectiva das cadeias globais de mercadorias. Utilizando esta estratégia de análise, será possível destacar os diversos níveis e atores econômicos que intervêm nas articulações que fazem parte da cadeia de produção da indústria da confecção e do vestuário. Transita-se por níveis globais, nacionais e locais no intuito de compreender a configuração de nichos econômicos e mecanismos específicos de inserção ocupacional destes imigrantes. Ao mesmo tempo, procura-se reconhecer as complexas relações sociais que contribuem para a reprodução de relações de subordinação e exploração nos espaços das oficinas. Como atributo específico da perspectiva das cadeias globais, tentar-se-á reconhecer a participação de atores institucionais por meio de expressões de governança em diversos níveis desta cadeia.
\end{abstract}

Palavras-chave: Cadeias globais de mercadorias; imigrantes bolivianos; indústria de confecções e vestuário.

\author{
Magali Alloatti \\ Doutoranda em Sociologia \\ Política pela Universidade \\ Federal de Santa Catarina - \\ Brasil. \\ magalialloatti@gmail.com
}

\section{Para citar este artigo:}

ALLOATTI, Magali. A multidimensionalidade da imigração boliviana em São Paulo: perspectivas das cadeias globais como estratégia de análise. Revista PerCursos. Florianópolis, v. 15, n.28, p. $257-284$. jan./jun. 2014. 


\title{
The multidimensionality of Bolivian migration in São Paulo: the global chains perspective as a strategy of analysis
}

\begin{abstract}
This paper analyzes different dimensions of Bolivian immigration and its insertion in clandestine sewing factories in São Paulo, from the perspective of global commodity chains. Using this strategy of analysis it will be possible to distinguish the various levels and economic actors that intervene in the links that form the production chain of the clothing and textile industry. Global, national and local levels are approached in order to understand the configuration of economic niches and specific mechanisms of occupational integration of these immigrants. At the same time it tries to recognize the complex social relations that contribute to the reproduction of relations of subordination and exploitation in these work spaces. As a specific attribute of the global chains perspective it tries to recognize the simultaneous participation of institutional actors through expressions of governance at various levels of this chain.
\end{abstract}

Keywords: global commodity chains; Bolivian immigrants; clothing and textile industry 


\section{Introdução}

O presente artigo é o resultado de uma longa pesquisa sobre o fenômeno da migração boliviana para o município de São Paulo, realizada por meio de consulta a pesquisas recentes, da análise de dados secundários e de uma pesquisa hemerográfica da década de 2003 a 2013 no jornal A Folha de São Paulo. Diversos avanços desta pesquisa foram publicados ao longo do ano passado ${ }^{1}$, mas, finalmente, conseguiu-se amadurecer um trabalho completo, articulando aspectos econômicos e sociais. Considerando a importância, a magnitude, os desdobramentos e a permanência no tempo do fluxo migratório de bolivianos para o município de São Paulo, e para o estado em geral, é imperativo recortar a análise e escolher os elementos mais oportunos.

Existe uma convenção no meio acadêmico de duas diretrizes na hora de realizar uma pesquisa: ou o pesquisador pode se debruçar sobre um tema, ou sobre um problema nunca trabalhado, especialmente por seu caráter recente; também se pode tentar oferecer uma análise sobre um tema já trabalhado, mas com uma perspectiva ou enfoque que produza nova informação sobre um conhecimento já estabelecido. É esta segunda opção que foi escolhida para este artigo. O movimento migratório de bolivianos para São Paulo é um tema altamente complexo, que tem exigido dedicação e atenção de diversos estudiosos das migrações no Brasil, como Baeninger (2013), Silva (2006), Braga Martes (2009), Souchad (2013); Freitas (2009; 2013) e Silva (2013), entre outros.

Qual pode ser a nova perspectiva aqui oferecida? Em parte, a proposta surge das críticas formuladas por estudos migratórios sobre os enfoques economicistas que, em algum momento, pretenderam explicar as migrações. O que se define como enfoque neoclássico tem instaurado um entendimento de que os movimentos de pessoas podem ser explicados (inteiramente) a partir de pressupostos econômicos próprios desta perspectiva. É o que geralmente se define como movimentos push-pull, que pretende explicar escolhas, decisões e movimentos de pessoas a partir das melhores condições

\footnotetext{
${ }^{1}$ Cf. ALLOATTI, Magali. A configuração discursiva da imigração: exemplo de um modelo sociocognitivo no discurso jornalístico. Trabalho apresentado no VII Encontro Nacional Sobre Migrações, GT Migração - Abep , realizado em Belo Horizonte/MG, nas dependências da UFMG/Face/Cedeplar - Brasil, de 23 a 25 de outubro de 2013.
} 
existentes (em termos comparativos ou absolutos) em diversos espaços nacionais (CASTLES E MILLER 2005; SAYAD 1998; ARANGO 2003²). Como se trabalhará nas próximas páginas, as limitações deste enfoque, aliás evidentes, foram aparecendo progressivamente junto com a proliferação de pesquisas empíricas que trouxeram à tona a necessária discussão sobre aspectos como: objetivos pessoais, laços sociais, migrações familiares, expectativas, realização pessoal, busca da liberdade, entre outros aspectos.

A discussão sobre a pertinência das ferramentas econômicas para a análise de fluxos migratórios não é recente, nem pouco desenvolvida, mas resulta necessária cada vez que a chance de pesquisar estes movimentos aparece. No caso deste artigo, a proposta é resgatar alguns elementos da área da ciência econômica, mas desde outros enfoques e com outras interações. Será retomada a perspectiva das cadeias mercantis globais, a ser articulada, com ,especial atenção, com a análise local sobre o fenômeno em estudo. Em poucas palavras, o que se procura aqui entender, pelo menos de maneira parcial, são as relações e mecanismos econômicos e sociais que fazem com que o fluxo migratório em questão se mantenha ao longo do tempo a partir dos lucros que ele gera na inserção econômica destes imigrantes em um tecido de relações de índole local, regional, nacional e global.

Serão trabalhadas as relações entre grandes empresas e a contratação de imigrantes bolivianos em oficinas de costura ilegais na indústria do vestuário no município de São Paulo. Será possível reconhecer, assim, um amplo leque de questões relativas à inserção específica desses imigrantes em determinados nichos econômicos, assim como "a indústria da migração", que inclui diversas relações sociais. A principal contribuição é compreender como as condições de vida e trabalho destes imigrantes, sua inserção econômica e as relações entre eles são afetadas por aspectos econômicos; estes,

\footnotetext{
2 “[...] a explanação neoclássica das migrações tem a vantagem de combinar a perspectiva micro da adoção de decisões por parte dos indivíduos com a perspectiva macro dos determinantes estruturais. No plano macro, a teoria neoclássica é uma teoria da redistribuição espacial dos fatores de produção na resposta a diferentes preços relativos (RANIS e FEI, 1961, TODARO, 1976). As migrações resultam da desigual distribuição espacial de capital e trabalho. Em alguns países e regiões, o fator trabalho é escasso em relação com o capital e, em consequência, seu preço - o nível dos salários - é elevado, enquanto que em outros países ou regiões acontece o contrário. Em consequência, os trabalhadores são propensos a ir de países ou regiões onde a mão de obra é abundante e os salários elevados, contribuindo, assim, para a redistribuição dos fatores de produção e, em longo prazo, para a equiparação dos salários entre os distintos países, corrigindo desigualdades originais" (ARANGO, 2003. Tradução nossa).
} 
acredita-se, podem ser identificados pela análise de cadeias globais, o que permite reconhecer que grandes atores econômicos, situados num nível nacional ou internacional, podem condicionar e definir fortemente algumas realidades locais.

\section{Sobre as cadeias globais: sua riqueza analítica}

A escolha da perspectiva das cadeias globais de mercadorias tem como fundamento uma de suas contribuições mais valiosas: a capacidade de compreender articulações econômicas diversas, respeitando diversos níveis (global, regional, local) de interação. A principal referência sobre o tema é, sem dúvida, de Gary Gereffi, que tem definido as cadeias como:

[...] atividades implicadas no design, [na] produção e [na] comercialização de um produto apresentam-se [...] enraizadas em sistemas transnacionais de produção que ligam as atividades econômicas das firmas às redes tecnológicas, organizacionais e institucionais usadas para desenvolver, fabricar e comercializar mercadorias específicas" (GEREFFI apud COMERLATTO e LINS, 2008, p. 4. Grifo do autor.)

Para o autor, não se trata simplesmente de uma maneira de articular níveis de produção ou comercialização, mas de um enfoque que permite compreender as diversas e múltiplas articulações entre diversas instâncias espaciais a partir das suas relações econômicas ${ }^{3}$. Como destaca Lins, as cadeias globais não só destacam a importância da divisão do trabalho (que é um tema caríssimo a seu estudo), senão também obriga a pensar a questão da governança, entendendo-a como exercício do poder em diversos âmbitos e níveis das redes ${ }^{4}$. As relações de poder desdobram-se no espaço empresarial, o

\footnotetext{
3 "It consists of identifying the full set of actors that are involved in the production and distribution of a particular good or service and mapping the kinds of relationships that exist among them. The goal is to understand where, how and by whom value is created and distributed along a commodity chain (APPELBAUM and GEREFFI, 1994). Special attention is paid to the most powerful or lead firms in an industry, which are also known as chain drivers, because of their influence over other chain participants and their presumed importance as potential agents of upgrading and development" (BAIR, 2005 p. 157).

4 "[...] studies of existing GCCs (Global Commodities Chains) have focused primarily on the governance dimension - that is, the question of which firms in the chain are most able to control various aspects of the production process and how they appropriate and/or distribute the value that is created. Thus, to describe a chain's governance structure is to illuminate the nature of power relations that exist along a chain" (BAIR,
} 
que significa que determinadas firmas têm a capacidade de impor critérios de qualidade, preço e produção de bens; entretanto, também implicam um tecido de atores institucionais que interagem necessariamente no desenvolvimento das relações econômicas. Ou seja, é possível reconhecer o exercício de governança por parte dos atores econômicos e dos atores institucionais, assim como as diversas interações entre eles. Tratando-se de uma discussão do trabalho, de redes e de espaço, a ingerência e a ausência da capacidade estatal (em diversos níveis) de controlar e regular estas cadeias constituem tema central.

A perspectiva das cadeias globais resulta de grande riqueza analítica na hora de entender de maneira dinâmica as diversas relações entre os atores que nela intervêm, oferecendo um marco analítico para compreender alguns elementos fundamentais da globalização. Este enfoque é especialmente sensível ao funcionamento de empresas e nações, mas também à forma como “[...] os fatores institucionais e regulatórios podem moldar os prospectos de desenvolvimento na economia mundial" (GEREFFI, 2001 p. 34 $4^{5}$ ). Esta perspectiva destaca os diversos níveis de interação econômica, procurando identificar mecanismos e processos que estão acontecendo por cima e por baixo do nível do Estado-nação (GEREFFI apud COMERLATTO e LINS, 2008). Em outras palavras: é possível assim compreender que determinadas relações sociais e econômicas que acontecem em um espaço local devem ser entendidas necessariamente em relação a esse espaço, já que se trata de relações e disposições de atores que somente têm sentido nele. Ao mesmo tempo, porém, existem maneiras pelas quais estes tipos de configurações locais são inseridos de maneira exitosa numa cadeia global que explora estas condições, e cuja articulação funciona devido a estes arranjos locais.

Foram consultadas pesquisas empíricas realizadas na perspectiva de cadeias globais como elementos de apoio na hora de pensar as atividades e relações econômicas referentes aos trabalhadores imigrantes bolivianos na indústria da confecção e vestuário. Aspectos que se devem destacar a partir destas referências são:

a) pensar as articulações locais, nacionais e globais a partir da condensação do poder nas relações estabelecidas nestas cadeias; 
b) a determinação da produção, critérios e papéis de cada ator segundo as relações de poder;

c) a importância dos atores intermediários (agentes de importação, compradores, negociadores, agentes de exportação, entre outros) na reprodução das relações estabelecidas nestas cadeias (AGERGAARD; FOLD; GOUGH, 2009);

d) as desigualdades de poder nas expressões de governança por parte dos atores institucionais e os atores econômicos.

Como demonstram Comerlatto e Lins (2008) e Lins (2007), as diferenças de poder entre os atores econômicos fazem com que algumas firmas ou empresas consigam impor, aos outros agentes da cadeia, os critérios e parâmetros de produção. Isto deve ser entendido como um exercício efetivo do poder, já que as empresas que lideram estas cadeias "[...] definem o que deve ser produzido, [...] o modo como ocorre a produção, o momento em que esta há de ocorrer, a quantidade a ser produzida e o preço pelo qual se produz" (COMERLATTO e LINS 2008, p. 4). As diversas articulações entre os agentes econômicos destacam a importância de relações de subordinação e aceitação de alguns dos atores desta cadeia, especialmente os locais, como condição para continuar fazendo parte dela. Por outra parte, destaca-se a fraqueza da governança dos atores institucionais, locais ou nacionais, na sua incapacidade de promover o desenvolvimento local, no fracasso de convênios ou programas que procuraram um up-grading destes atores econômicos.

Para finalizar, é possível compreender que devemos identificar os elementos que expressam não só as articulações econômicas entre os atores que fazem parte da cadeia, mas também entendê-los a partir da dimensão do poder, buscando identificar relações de determinação e subordinação. A referência a pesquisas empíricas permitiu compreender que agentes econômicos locais, como as oficinas de costura clandestinas em São Paulo, funcionam e conseguem ter sucesso em termos de lucro a partir de uma configuração global e nacional de atividades relacionadas à indústria do vestuário. A importância das grandes firmas não deve ser desconsiderada, especialmente porque a indústria do 
vestuário em São Paulo é o tipo definido como cadeias comandadas por compradores ${ }^{6}$, pelo fato de que os grandes comerciantes são os que organizam e coordenam as relações desta cadeia:

[...] referem-se às indústrias nas quais os grandes comerciantes e fabricantes de marcas têm o papel de pivô no estabelecimento das redes de produção descentralizada em uma variedade de países exportadores; [trata-se] de indústrias como do vestuário, sapatos, brinquedos" (GEREFFI, 2001 p. 14, 15 e 16. Tradução nossa).

\section{A indústria do vestuário no Brasil}

Antes de aprofundar a análise dos aspectos que nos interessam, é fundamental descrever alguns traços característicos da produção de vestuário no Brasil. Trata-se de um setor econômico de alta importância e que, atualmente, se encontra frente a um panorama pouco animador devido à concorrência das importações, com grandes repercussões nos índices de emprego.

Segundo a Associação Brasileira de Indústria Têxtil e de Confecção (Abit), o Brasil coloca-se como o sétimo maior produtor mundial de têxteis e vestuário. Tem mais de 100 mil indústrias de confecção - formais e informais -, que chegam a produzir 7,2 bilhões de peças ao ano. Esta atividade emprega perto de dois milhões de trabalhadores (sendo $75 \%$ mulheres). Do total de empregos, 1,2 milhão se refere à atividade de confecção de vestuário, representando o segundo segmento que mais gera emprego no País. É importante destacar que as exportações de têxteis e vestuário do Brasil representam 0,5\% da produção mundial, o que significa que sua produção é destinada principalmente ao mercado interno. Das indústrias de confecção, as de pequeno porte representam a maior quantidade, $71 \%$ do total, localizadas principalmente no estado de São Paulo (zona metropolitana $)^{7}$.

\footnotetext{
${ }^{6}$ A proposta das cadeias globais de mercancias de Gereffi reconhece dois tipos centrais de cadeias produtivas: dirigidas por produtores e dirigidas por compradores. No caso da primeira, "[...] são aquelas em que os grandes fabricantes, comumente transnacionais, têm o papel central na coordenação das redes de produção [...] é característico das indústrias de capital e com tecnologia intensiva, como as automotrizes, aviões, computadores, etc." (GEREFFl, 2001. p. 14. Tradução nossa).

7 Disponível em: <http://www.practicaltex.com/rapida-visao-das-industrias-do-vestuario-no-brasil.php> Acesso em: 2 fev. 2014.
} 
É possível observar uma significativa queda na produção deste setor no ano 2013, sendo o ponto culminante de uma tendência que se vem aprofundando desde 2008. 0 presidente do Sindivestuário, Ronald Masijah, atribui o declínio na produção ao aumento da entrada de importados no País. "De 2008 para cá, aumentou 272\% o número de produtos importados. Os importados entram no País porque não conseguimos competir [...] Nosso parque industrial é moderno; o problema são os tributos" ${ }^{8}$. No período de janeiro-agosto de 2013 , o setor em questão apresentou uma queda de $13,44 \%$ no estado de São Paulo (acompanhado de uma queda pequena - 0,73\% - do setor têxtil). A principal concorrência que o setor enfrenta atualmente é a importação de peças de vestuário asiáticas. No primeiro semestre do ano (janeiro-agosto), as importações têm crescido consideravelmente, chegando a $6,75 \%$ no estado de São Paulo, segundo dados de Ministério de Desenvolvimento Indústria e Comércio. Em termos de valor, nos primeiros oito meses do ano, as importações de têxteis e confeccionados cresceram 6,7\% (em US\$).

A mencionada queda na produção de vestuário vem acompanhada de duas tendências complementares. Por uma parte, a diminuição do emprego; por outra, um aumento constante nas vendas de varejo devido às importações ${ }^{9}$. Em relação ao primeiro ponto, dados da Federação das Indústrias do Estado de São Paulo (FIESP) mostram que no mês de agosto o setor têxtil paulista registrou uma queda de 1,8\% entre contratações e demissões em relação ao mês anterior. Já no segmento de confecção de vestuário, houve queda de $2 \%$. Se compararmos com os últimos 12 meses, a retração de postos de trabalho ainda é elevada, com redução de 5,5\% no segmento de vestuário e de 2,4\%, no têxtil.

Em relação ao segundo ponto, é interessante destacar que nos primeiros sete meses do ano, de janeiro a julho, o volume de vendas no varejo apresentou um aumento de 3,1\% em relação ao mesmo período do ano anterior no estado de São Paulo. O setor de varejo de roupas e confecções, inclusive, tem incorporado muitas das pessoas que ficaram desempregadas no setor da produção. Isto quer dizer que a tendência de compra de roupa continua sendo a mesma (com possíveis variações) e que são as peças

\footnotetext{
${ }^{8}$ Disponível em: <http://www.fiesp.com.br/noticias/producao-da-cadeia-textil-deve-crescer-27-em-valoresem-2013-aponta-relatorio-do-iemi/>. Acesso em: 6 fev. 2014.

${ }^{9}$ Disponível em:

<http://www.textilia.net/materias/ler/textil/conjuntura/producao_de_vestuario_sofre_queda_em_sao_paul o>. Acesso em: 4 fev. 2013.
} 
importadas que estão sendo colocadas nos varejos e lojas de venda que explicam a queda da produção doméstica de vestuário e o aumento das importações do Brasil ${ }^{10}$.

\section{Sobre São Paulo como destino e inserção dos imigrantes bolivianos}

Até aqui foi possível resenhar alguns aspectos macro a respeito da cadeia global da venda e produção de vestuário no caso do Brasil, em geral, e do estado de São Paulo, em particular. As primeiras conclusões que se podem tirar é que as quedas na produção e a forte concorrência com as importações se devem à inserção do Brasil no cenário mundial, frente a outros países produtores e exportadores de peças de vestuário. $\mathrm{O}$ desafio agora é tentar compreender de que maneira as oficinas clandestinas, que contratam imigrantes bolivianos em condições irregulares, fazem parte desta cadeia. Paralelamente, identificar por que elas conseguem um relativo sucesso que garante sua permanência na cadeia. É fundamental reconhecer as relações e articulações entre os diversos níveis, como o local (constituído pelas oficinas), o nacional (constituído pelas firmas brasileiras que as contratam) e o internacional (considerando as empresas estrangeiras). Também será preciso considerar as características macro previamente detalhadas. É fundamental lembrar-se da importância dos atores intermediários, que outras pesquisas têm destacado, assim como os esforços por parte da governança local (seja Ministério de Trabalho e Emprego, sindicatos, associações, etc.), de lidar com a progressiva importância que a contratação de imigrantes indocumentados tem merecido na esfera pública a partir da mídia.

\subsection{Inserção econômica dos bolivianos}

Como se insere a problemática da contratação de imigrantes bolivianos indocumentados nas oficinas de costura informais? Vejamos, primeiramente, alguns dados sobre a situação deste fluxo migratório e sua inserção econômica. É importante conseguir dar conta da porcentagem significativa de pessoas indocumentadas que

\footnotetext{
${ }^{10}$ Disponível em: <http://www2.uol.com.br/canalexecutivo/notas131/2409201313.htm>. Acesso em: 2 fev. 2014 .
} 
trabalham em condições irregulares, fato que lembra muito a problemática do trabalho escravo. Os imigrantes, em condições irregulares ou indocumentados, encontram-se altamente vulneráveis a situações de exploração, gerando cenários de trabalho e condições de moradia deploráveis (como amontoamento, doenças, entre outros aspectos).

Para os bolivianos, o estado de São Paulo é um território de destino há mais de três décadas. No ano 2000, a Bolívia estava entre os três primeiros países de emigração para São Paulo e no primeiro lugar no ano 2010 (DESENVOLVIMENTO, 2012). Este grande contingente de imigrantes tem como destino a ocupação (subcontratação) em oficinas de costura clandestinas - no ramo da confecção -, com uma presença tão significativa que tem influenciado culturalmente o espaço urbano dos bairros onde este tipo de atividade se localiza e onde mora - distritos como Vila Maria, Belém e Casa Verde, além de outras regiões próximas às instalações fabris (BAENINGER 2012 apud DESENVOLVIMENTO, 2012).

\begin{abstract}
Concretamente, a partir de observações (justificadas) tais como a concentração residencial dos bolivianos nos bairros centrais de São Paulo, o Bom Retiro, o Brás, o Pari, principalmente, e sua concentração no setor de atividade da confecção onde, através de parcerias complexas e antigas com imigrantes coreanos, trabalham em oficinas de pequeno e médio porte, estabeleceu-se gradativamente a ideia de que os bolivianos detêm hoje o monopólio do trabalho nas oficinas de costura de médio e pequeno porte e vivem em bairros onde seriam os únicos imigrantes, ou seja, teriam formado espaços residenciais mono-étnicos (além dos brasileiros) e nicho econômicos fechados" (SOUCHAUD, 2013. p. 77).
\end{abstract}

De acordo com Silva (2013), a principal ocupação dos nascidos na Bolívia, residentes no município de São Paulo, segundo a classificação brasileira de ocupações para o ano 2000, é de operadores de máquinas de costura de roupas, superando todas as outras atividades. Isto demonstra que o fluxo migratório boliviano, de acordo com Baeninger (2013) e Freitas (2009), tem como principal objetivo sua alocação no trabalho em oficinas de costura sob condições de subcontratação, fazendo de São Paulo um destino ao longo das últimas três décadas: 
Essas interações entre Bolívia e Brasil, vinculam-se, sobretudo, à geração de atividades do circuito inferior da economia urbana decorrentes do circuito espacial de produção de vestuário, que se implanta em lugares específicos no território brasileiro, ou seja, é a divisão territorial do trabalho que acaba condicionando os processos migratórios. A presença de bolivianos na cidade de São Paulo associada ao ramo do vestuário mostra o território usado, a partir do lugar (SILVA, 2013, p. 1317. Grifo nosso).

Segundo o Censo do IBGE do ano 2010, das pessoas que residem hoje no Brasil, 27.260 são bolivianos, dos quais 14.597 são homens e 12.663, mulheres. Em uma matéria publicada no jornal La Razón, um dos principais da Bolívia, a Chancelaria boliviana tem registro de 62.950 bolivianos legais em todo o território brasileiro ${ }^{11}$. Entretanto, o Instituto de Migrações e Direitos Humanos, ligado à Conferência Nacional dos Bispos do Brasil (CNBB), aponta entre 250 mil e 300 mil bolivianos indocumentados vivendo em São Paulo, enquanto o Ministério da Justiça calcula 50 mil irregulares (SILVA 2013).

Se considerarmos estes dados, embora pouco fidedignos, poderíamos esperar um aumento das estatísticas oficiais de contratação de imigrantes bolivianos. Porém, os dados de permissão de trabalho do Ministério de Trabalho e Emprego demonstram o contrário. Para o Brasil inteiro, as autorizações de trabalho para pessoas bolivianas, no ano 2010, foram de 85, sendo para São Paulo, 22, no total. No ano 2011, para o Brasil foram 72; para São Paulo, 11. No ano 2012, para o Brasil inteiro foram outorgadas 82 permissões, enquanto para São Paulo, 20. Finalmente, no ano 2013, foram dadas 12 permissões em nível nacional, sendo oito no estado de São Paulo ${ }^{12}$. A melhor conclusão que se pode tirar destes dados é a contundência da quantidade de imigrantes bolivianos indocumentados que moram no Brasil e em São Paulo, e que se encontram trabalhando na atividade de confecção de vestuário em condições irregulares.

\footnotetext{
11 Disponível em: <http://www.la-razon.com/nacional/TSE-prioridad-paises-empadronamientoelecciones_0_1859214150.html>. Acesso em: 13 jul. 2013.

12 Disponível em: <http://portal.mte.gov.br/data/files/8A7C812D3DCADFC3013EB3D9D9EA28Eo/5.1\%20\%20Mercosul\%20-\%20Autoriza\%C3\%A7\%C3\%B5es\%20concedidas\%20por\%20situa\%C3\%A7\%C3\%A30.pdf> e <http://portal.mte.gov.br/data/files/8A7C812D3DCADFC3013EB3D9DCB7291C/5.2\%20-\%20Mercosul\%20\%20Autoriza\%C3\%A7\%C3\%B5es\%20concedidas\%20a\%20por\%20UF.pdf>. Acesso em: 13 jul. 2013. Acesso em: 13 jul. 2013.
} 
Pode-se deduzir que as informações sobre a população boliviana imigrante em São Paulo, e no Brasil, são, no mínimo, escassas e inexatas. A crítica destes dados deve reconhecer como pano de fundo as políticas migratórias do Brasil e do MERCOSUL, que hoje procuram facilitar a circulação e a residência de pessoas nos países membros. Nosso país tem aplicado varias anistias: a primeira, na década de 80; a última, no ano 2009. Todas tiveram como objetivo regularizar os imigrantes em condições indocumentadas. Nestas ocasiões, os imigrantes bolivianos representaram uma alta porcentagem no total de pessoas que buscaram regularizar sua situação, embora as condições de normalização da situação fossem difíceis de cumprir (valor das taxas, tempo de dedicação, documentos do país de origem a ser apresentados). Segundo vários pesquisadores (SILVA 2006; SILVA, 2013; BAENINGER, 2013), o principal obstáculo foram as exigências de documentos e tempo, o medo de se apresentar à Polícia Federal (autorizada a realizar estes trâmites) e o temor da denúncia de trabalho em condições irregulares, especialmente no caso das oficinas de costura.

\subsection{Relação entre a indústria do vestuário e a contratação irregular}

Na pesquisa hemerográfica realizada pelo jornal Folha de São Paulo nos anos 2003-2013, foi possível observar que, quanto maiores eram os ganhos da indústria de vestuário e confecção no ano, maior era a presença da problemática dos imigrantes bolivianos na mídia. Foi até possível observar, segundo este jornal, uma correlação entre o crescimento deste setor industrial e os valores absolutos de imigrantes bolivianos que chegaram a São Paulo nos anos referidos. No período destacado, os anos de 2004 e 2007/2008 parecem constituir momentos de auge da atividade econômica mencionada, que colocou em discussão a problemática da contratação ilegal de bolivianos. Este foi o clima que precedeu o Convênio de Regularização e Residência de Imigrantes Bolivianos no Brasil, criado em 2004, com início de funcionamento no ano seguinte.

É interessante destacar que no Pacto contra a precarização e pelo emprego $e$ trabalho decentes em São Paulo - cadeia produtiva das confecções ${ }^{13}$, celebrado pelo

\footnotetext{
${ }^{13}$ Disponível em:
} 
Ministério de Trabalho e Emprego e a Superintendência Regional do Trabalho e Emprego de São Paulo, de 24 de julho de 2009, se faz referência à grande ação realizada pelo grupo “Dignidade para o trabalhador migrante”, que, a partir de junho do ano 2007, se propunha "melhorar as condições de trabalho dos imigrantes que trabalham no ramo de confecções em São Paulo em qualquer função da sua cadeia produtiva". Esta era a primeira e principal premissa deste pacto. Segundo o documento citado, foi a partir de outubro de 2007 que a Superintendência Regional do Trabalho e Emprego em São Paulo deu início ao Programa de Combate à Fraude na Relação de Trabalho e à Terceirização irregular. Este documento exibe como elemento fundacional e necessário o diálogo com diversas instituições governamentais, comerciais e sociais (ONG, Associação dos Bolivianos Bolbra -, Pastoral do Migrante).

Estes eventos de 2007 e 2008 constituíram o marco a partir do qual se desenvolveu a anistia realizada pelo governo brasileiro em 2009, utilizada como antecedente para o Convênio de Livre Residência para países membros e associados (Bolívia) do MERCOSUL em 2010. É necessário destacar que, no total, foram 41.816 estrangeiros que regularizaram a sua situação, mais de 40\% dos quais bolivianos (16.881). O principal destino dos estrangeiros, segundo os dados desta anistia, foi São Paulo, onde se fixaram 34 mil imigrantes ilegais, ou mais de $80 \%$ do total, em busca de oportunidades de trabalho ${ }^{14}$.

Estes antecedentes, como o pacto contra a precarização do emprego, destacaram principalmente as condições dos trabalhadores imigrantes indocumentados pelos efeitos das atividades terceirizadas. A aplicação da anistia aos imigrantes irregulares pode ser interpretada como esforço de governança local, de acordo com o que foi exposto no caso da pesquisa de Comerlatto e Lins (2008). Tanto o nível municipal e estadual, quanto o nacional expressam não só o reconhecimento da problemática, senão também a necessidade de resolver situações laborais destes imigrantes ao longo de muito tempo. É evidente que a relação entre o crescimento da indústria de confecção e vestuário e o destaque cada vez maior desta problemática na mídia se forja a partir da visibilidade da

<http://www.justica.sp.gov.br/downloads/biblioteca/Pacto\%20da\%2oind\%C3\%BAstria\%20t\%C3\%AAxtil\%20contr a\%200\%20trabalho\%20escravo\%20em\%20S\%C3\%A30\%20Paulo.pdf>. Acesso em: 15 jul. 2013.

14 Disponível em: <http://www.estadao.com.br/noticias/nacional,brasil-anistia-41816-estrangeiros-emsituacao-irregular,491657,o.htm>. Acesso em: 14 out. 2013. 
situação destes imigrantes. O fato de a problemática ganhar visibilidade é um sinalizador das transformações sociais e culturais que tal presença tem gerado ao longo do tempo ${ }^{15}$. Embora os esforços por parte do Ministério do Trabalho, com suas campanhas, seja de proteger os trabalhadores, a principal interrogação das pesquisas sobre o tema é se estas oficinas clandestinas onde os imigrantes bolivianos trabalham poderiam se manter eficazes e competitivas se fossem regularizadas (SOUCHAD, 2013, p. 86).

\subsection{Formas de contratação, regimes de trabalho e condições de vida}

Nos termos de Silva (2006), parte da inserção dos imigrantes bolivianos nestas atividades, indocumentados e em situação semelhante à do trabalho escravo, respondeu à reestruturação econômica e produtiva expressa no paradigma da acumulação flexível:

Do ponto de vista ocupacional, os bolivianos que entraram no país, a partir da década de 1980, trabalham, em sua maioria, no setor da costura, por ser esse um segmento do mercado de trabalho que não exige experiência prévia nem idade mínima para o trabalho, incorporando mesmo menores. Do trabalhador se exige apenas muita coragem para se adaptar às condições insalubres de trabalho, uma vez que é um setor no qual não há nenhuma regulamentação das relações trabalhistas. Tal modo de produção se enquadra no modelo de "acumulação flexível" do capital, em que a produção se dá com base na quantidade de peças que o trabalhador é capaz de costurar. Nesse caso, as regras de trabalho são permeadas por relações de parentesco e amizade, ensejando, assim, espaço para a subjugação dessa mão-de-obra, sobretudo das mulheres (HARVEY, 1992, p.146, apud SILVA, 2006, p. 161. Grifos nossos).

Esta forma de contratação de trabalho se explica principalmente pela maneira como funciona a retribuição econômica do trabalhador. Desde os anos 80, os ganhos nas oficinas de costura clandestinas dependem da quantidade de peças bem confeccionadas que o trabalhador consegue fazer numa jornada (no máximo 40 centavos de real por peça). Sendo assim, para ganhar mais, é necessário trabalhar mais horas ${ }^{16}$. A ilegalidade

15 Disponível em: <http://www.lotusidiomas.com.br/boletim/84-novidades/109-sao-paulo-tem-bairrosboliviano-e-coreano.html>, <http://reporterbrasil.org.br/2006/07/kantuta-e-um-pedaco-de-bolivia-na-capitalpaulista/>, <http://vejasp.abril.com.br/estabelecimento/feira-boliviana-praca-kantuta> <http://www.olharturistico.com.br/praca-kantuta/>. Acesso em: 15 out. 2013.

16 Para mais detalhes sobre a descrição deste tipo de trabalho, consultar A configuração discursiva da 
da contratação constitui um aspecto central nesta configuração econômica por diversos motivos:

a) a partir desta forma de retribuição, os trabalhadores não são registrados com carteira assinada;

b) a continuidade do contrato laboral depende da satisfação da demanda estabelecida;

c) não existem riscos de superprodução, sendo o trabalhador que amortiza os excedentes.

A alocação destes imigrantes em oficinas de costura, em condições de trabalho escravo e de isolamento, recebendo por peça, força os indivíduos a trabalhar numa média de 12 a 16 horas por dia (SOUCHAD; FREITAS 2013; BRAGA MARTES, 2009). O setor da costura parece ser um dos principais nichos econômicos de destino para estes imigrantes devido à inserção histórica desde os anos 80, o que não é um dado menor. A partir de uma ocupação laboral que se mantém no tempo, as redes sociais que permitem a migração se articulam a partir destes empregos. Assim, os bolivianos que chegam ali conseguem entrar em contato (se é que não conheciam previamente alguém) nessa atividade, reproduzindo este tipo de trabalho.

Um aspecto central da irregularidade destas atividades e de seus locais são as condições de trabalho e moradia. Trata-se, geralmente, de jornadas de trabalho entre $12 \mathrm{e}$ 16 horas por dia. Outro dado, é que geralmente eles moram no mesmo espaço em que trabalham. Tratando-se de um tipo de migração e alocação familiar, os imigrantes alugam casas pequenas entre várias pessoas, o que gera consequências que vão além do trabalho excessivo. Registram-se determinadas doenças, como a tuberculose e enfermidades respiratórias, por falta de circulação de ar ou por dedicação de muitas horas a essa atividade (MELO; CAMPINAS 2010, p. 29). A falta de integração das crianças à escola 
(CHANG WALDMAN, 2013) faz com que a vida dos filhos se restrinja à casa, compartilhando a jornada dos pais nas condições descritas ou, muitas vezes, começando a trabalhar muito cedo.

\subsection{Histórico de transformações na indústria da confecção, mudanças nos processos produtivos e multidimensionalidade da participação dos bolivianos}

Segundo Souchad e Freitas (2013), não é possível compreender o funcionamento e a estrutura do sistema de contratação de imigrantes bolivianos no setor de confecções e vestuário, nem as condições que propiciam sua exploração, se não se compreenderem primeiramente as transformações históricas e econômicas que a atividade tem sofrido ao longo das últimas décadas. Analisar estes processos permitirá, conjuntamente, visualizar de maneira mais clara as articulações em termos de cadeias globais que já se mencionaram neste artigo, o que contribui com o argumento aqui proposto. É preciso considerar esta atividade econômica e suas diversas articulações ao longo do tempo para poder compreender a força que determinadas empresas e atores econômicos exercem atualmente.

Para Souchad (2013), o ponto de partida é compreender que o setor de confecções tem experimentado uma forte reestruturação produtiva, especialmente no período de 1977 a $1999^{17}$. Progressivamente, a indústria de transformação foi perdendo espaço frente à importação de produtos, o que levou a uma forte reestruturação do setor. A forçada

\footnotetext{
17 “Entre 1977 e 1999, na RMSP, a concentração da população economicamente ativa (PEA) na indústria de transformação passou de $38 \%$ a $19 \%$, enquanto passava de $37 \%$ a $51 \%$ nos serviços (com exceção dos "serviços pessoais") (MEYER, GROSTEIN, BIDERMAN, 2004, p. 112). Outra fonte (a Secretaria de Economia e Planejamento - SEP -, Convênio Seade-Dieese, Pesquisa de Emprego e Desemprego - PED) aponta, para o município de São Paulo, que a concentração do emprego na indústria de transformação passou, entre 1985 e 2009 , de $29,8 \%$ para $15,3 \%$ do total. No mesmo período, os ocupados do setor formal (descontando a categoria dos "serviços domésticos") passaram de 44,0\% a 58,1\%. A intensa pressão no setor industrial, setor que teve que reduzir seus custos de produção para poder competir com os produtos estrangeiros, principalmente asiáticos, implicou diferentes modalidades de transformação, às vezes combinadas, distintamente aplicadas entre os subsetores industriais. No caso da confecção paulistana, enquanto unidades de produção desapareceram, as que se mantiveram ou, até, foram aparecendo, tiveram que passar por uma ou várias das seguintes modalidades de adaptação, muitas vezes combinadas: a deslocalização, a modernização, a reestruturação" (SOUCHAD, 2013, p. 78 e 79).
} 
modernização desta atividade implicou uma série de mudanças que tinham como principal objetivo ganhos na produtividade. Enquanto, por uma parte, isto implicou a incorporação de melhoras qualitativas, inovações e investimento na automatização e robotização das atividades, por outra, provocou a proliferação de oficinas de pequeno e médio porte (convém lembrar que são as que atualmente representam a maioria das unidades econômicas do setor). A consolidação deste tipo de oficinas, no esforço de representar menores custos de produção, promoveu a difusão de oficinas clandestinas que, na sua organização, incorporou populações de imigrantes internacionais indocumentados. Como explicam vários autores (SILVA apud SOUCHAD, 2013), estes imigrantes não só eram trabalhadores nestas oficinas, mas, ao longo do tempo, passaram a ser capatazes e até donos.

É possível compreender que grande parte do sucesso destas oficinas se baseou nas características de produção flexível previamente detalhada, ou seja, elas conseguem responder aos prazos estipulados pelos contratantes fazendo com que os horários e dedicação dos trabalhadores variem segundo a demanda realizada. Paralelamente à proliferação destas oficinas, Souchad (2010, 2013) destaca o aparecimento de oficinas familiares sustentadas em um tipo de migração familiar e por redes sociais. Tanto um casal, como uma família ou um grupo pequeno de conhecidos conseguia, a partir de contatos fornecidos pelas redes sociais de migração, conformar um grupo e estabelecer uma unidade de trabalho, como uma oficina de costura.

Para finalizar, é preciso compreender que parte desta proliferação e consolidação de oficinas de costura de trabalho de imigrantes indocumentados se explica pela substituição da mão de obra doméstica. Devido a diversas transformações econômicas, um aumento no nível de escolaridade e a diminuição da migração interna, como fatores principais, fizeram com que os brasileiros procurassem salários mais altos e uma distribuição de renda melhor. A depreciação do trabalho de costureiro e a demanda por trabalhadores dentro do modelo de produção flexível abriu as portas para imigrantes em condições de indocumentados que consolidaram, progressivamente, as mudanças produtivas. A aceitação das difíceis condições de trabalho não só se deve a estas exigências econômicas, mas também à vulnerabilidade da sua condição de 
indocumentados. Assim, podemos sintetizar que "[...] a presença dos imigrantes internacionais na confecção em São Paulo é a consequência, ao mesmo tempo, de uma chamada de mão de obra e de uma reestruturação produtiva" (SOUCHAD 2013 p. 82).

Ao longo das décadas de 80 e 90, a produção e a organização das oficinas de costura se encontravam sob o comando de imigrantes coreanos, que foram os primeiros a se inserir historicamente neste nicho econômico. Eles começaram a contratar os imigrantes bolivianos na atividade de costura a partir do processo da reestruturação econômica previamente comentada, buscando principalmente colocar os seus produtos no mercado interno num momento altamente recessivo da indústria do vestuário. Como demonstra Tavares de Freitas (2013), em meados da década de 90 a ligação dos dois grupos de imigrantes (coreanos e bolivianos) começa a se dissolver e, progressivamente, a aparecer oficinas de costura comandadas por bolivianos que exploram trabalhadores bolivianos. Este é um aspecto fundamental que é preciso detalhar.

A partir da análise da imprensa local, Freitas (2009) consegue demonstrar que a organização de oficinas de costura ilegais, organizadas por bolivianos, se orienta principalmente à contratação de outros bolivianos. Característica importante deste fenômeno é que começam a aparecer publicamente evidências de condições inumanas de trabalho, fazendo com que a problemática do trabalho escravo dos bolivianos ganhe cada vez maior presença. Enquanto a população de coreanos ligados à atividade de confecção vai progressivamente se formalizando, a proliferação de oficinas de costura comandadas por bolivianos se explica pela imigração desse povo graças às redes sociais e a contatos pessoais, e por sua transformação em pequenos empreendedores.

O recrutamento de conterrâneos para o trabalho nessas condições se explica por diversos fatores. Por uma parte, pela inserção econômica e por um perfil destes trabalhadores, derivado da sua condição de indocumentados, que os tornam vulneráveis às exigências dos contratadores. Os donos das oficinas conhecem os riscos da situação, assim como os medos de perder o emprego por eventuais denúncias. Eles utilizam estas vulnerabilidades para mantê-los trabalhando nos seus empreendimentos. 
Por outro lado, existe um aspecto fundamental para compreender o recrutamento que se refere à indústria da migração. Muitos dos donos de oficinas agenciam os contatos e a logística necessária para articular a busca de trabalhadores na Bolívia, o transporte e até mesmo os caminhos recomendados para o ingresso ao Brasil, assim como sua alocação (moradia e trabalho). Como explica Freitas (2013), esse fluxo migratório é uma ação coletiva, por envolver um grupo de pessoas que migra, podendo ser uma família ou uma rede mais extensa. Isto faz com que a organização e a logística de contratação (que começa na Bolívia) e o transporte e a alocação sejam economicamente rentáveis, porque se trata de um grupo de pessoas que vêm com o mesmo objetivo e que tentarão, segundo suas possibilidades, permanecer juntos. Sendo assim, os contratadores alocam famílias inteiras (com amigos e parentes) em uma moradia só, que será ao mesmo tempo seu local de trabalho.

Silva, depois de muitos anos de pesquisa e trabalho sobre este fenômeno, consegue explicar:

Em geral, o oficinista que foi à Bolívia buscar seus trabalhadores ofereceIhes casa e comida, propiciando, assim, a emergência de relações de dependência de um para com o outro, em razão de um "favor" que o empregador fez para com seus empregados. Esses, por sua vez, deverão trabalhar para ele, pelo menos por um ano [...] Vale notar que existem redes de agenciamento de mão-de-obra na Bolívia, em cidades como La Paz, de onde vem grande parte dos bolivianos que vivem em São Paulo, e Santa Cruz de La Sierra, cidade mais próxima do Brasil e, portanto, última etapa antes da saída do país. O custo da viagem para o emigrante pode variar, dependendo do trajeto escolhido. Para quem opta pela entrada por Corumbá (MT), pode custar cerca de US\$120. Porém, o risco de ser detido por um agente federal é maior. Já quem escolhe a rota do Paraguai terá que enfrentar uma longa e exaustiva viagem até chegar à Ciudad del Leste, para depois cruzar a fronteira e entrar no Brasil por Foz do Iguaçu (PR). O custo desse trajeto pode chegar a US\$ 160 (SILVA 2006, p. 166 e nota de rodapé 2, p. 169).

A partir disto, é possível identificar os donos das oficinas de costura como atores intermediários, sem os quais seria impossível compreender o funcionamento e a persistência destas oficinas. Eis aqui uma das riquezas analíticas da perspectiva das cadeias globais. Ela oferece a possibilidade de identificar estes atores econômicos e 
compreender a sua importância na articulação de diversas atividades econômicas. Os donos das oficinas não só contratam trabalhadores compatriotas em condições inumanas de trabalho, forçando-os a trabalhar uma média acima de 12 horas por dia e fazendo com que a sua ocupação dependa da demanda que ingressa na oficina, mas também articulam uma logística de recrutamento e transporte e reproduzem as condições de vulnerabilidade (lembre-se aqui que o traslado da Bolívia para o Brasil é sempre ilegal), necessárias para manter sobre eles o poder.

Estes agentes econômicos conseguem articular um fluxo migratório internacional e constante a partir da sua posição no processo produtivo, baseando-se no conhecimento das condições da mão de obra necessária para manter os lucros das suas atividades econômicas. Deve destacar-se, como informa a Abit, na comparação do custo da mão de obra entre os principais países produtores de vestuário e têxtil, que o Brasil supera amplamente seus competidores ${ }^{18}$. Isto permite compreender a proliferação de oficinas de trabalhadores indocumentados, no esforço por manter as peças produzidas a um custo competitivo em relação ao das importações, lembrando que a principal orientação da produção do vestuário no Brasil é o mercado interno.

\subsection{Breve menção do mercado interno e aos esforços de governança}

Considerando a forte orientação da indústria do vestuário para o mercado interno, é preciso fazer algumas considerações sobre a relação entre estas oficinas de costura que contratam imigrantes bolivianos e seus compradores. Na pesquisa hemerográfica citada, foi possível identificar que os principais clientes são grandes marcas brasileiras do mercado de indumentária e vestuário. Em 2007 (um dos momentos de destaque desta atividade econômica), a Folha de São Paulo publicou uma matéria ${ }^{19}$ que tratava sobre os convênios e os acordos contra a contratação de imigrantes indocumentados e o trabalho escravo, realizados por um grupo formado pelas lojas de varejo mais importantes do

\footnotetext{
18 Segundo a publicação para o ano 2007 da ABIT, o custo da mão de obra por hora no Brasil é de 3,27U\$, enquanto para China era de 0,55U\$, Paquistão de 0,42U\$ e Bangladesh de 0,28U\$. Disponível em: <http://marketingfuturo.com/industria-do-vestuario-no-brasil/>. Acesso em: 2 fev. 2013.

${ }^{19}$ Disponível em:

<http://acervo.folha.com.br/resultados/?q=imigrantes+bolivianos\&site=\&periodo=acervo\&x=4\&y=15>. Acesso em: 7 fev. 2014 .
} 
Brasil, entre elas a Renner, as lojas Marisa, a Riachuelo e a C\&A. Pela correlação entre as condições de produção e seu crescimento, as empresas citadas se comprometiam a não estabelecer vínculos comerciais com fornecedores que produzissem suas peças nestas oficinas irregulares.

É interessante destacar que, na contratação de trabalho terceirizado, não é a marca que contrata, senão as oficinas. Antes deste convênio, as grandes empresas não recebiam punições. As fiscalizações, quando encontram oficinas clandestinas, as fecham e os imigrantes indocumentados são deportados. A partir do acordo do ano 2007, estas firmas podem ser punidas, sendo a maior pena uma multa de até dez mil reais. Observese que todas as formas de punição são econômicas. A conexão entre estas oficinas e as firmas foi estabelecida pelo achado de etiquetas de marcas exclusivas destas empresas na confecção das oficinas. O caso foi da Blue Steel, da Renner e de uma marca exclusiva das Lojas Marisa. O que aconteceu, posteriormente, é que algumas destas firmas continuaram contratando oficinas clandestinas de confecção, mas aplicavam as etiquetas uma vez que as peças chegavam à loja, para evitar a conexão nas inspeções do Ministério de Trabalho e Emprego.

Dois aspectos devem ser adicionados a esta descrição. O primeiro a se destacar na matéria da Folha é o enaltecimento da postura das empresas que, ao assinar o convênio, expressamente apoiavam a promoção da contratação de trabalhadores com carteira assinada. O segundo, enfatizado pela Folha, eram as ações de empresas como a Renner e as Lojas Marisa por denunciarem o tipo de oficinas com empregados nas condições condenadas pelo convênio.

Este tipo de relação entre as grandes firmas domésticas e estrangeiras (como é o caso de $(\& A)$ e as oficinas clandestinas tem duas consequências a se destacar desde a perspectiva das cadeias globais. Por uma parte, é importante compreender que são as empresas que determinam o que deve ser produzido, como e quando. Isto se traduz em determinado tipo de demanda que impõe um modo de trabalho previamente acertado. As oficinas recebem pedidos de quantidade e tipo de peças em prazos curtos, atendidos por uma jornada de trabalho com base no valor da peça, o que compromete o trabalhador em largas horas de dedicação. O segundo aspecto diz respeito a cadeias 
comandadas pelo comprador. Neste caso, não são as oficinas contratadas que desenvolvem o design dos produtos, mas o contratante, o que, se contribui para uma relação de dependência e subordinação e restrição, seja de criar designs, seja de liberdade com outros tipos de lojas e compradores, por outro compensa pelo reforço na manutenção dos vínculos entre oficinas e firma.

O tipo de relação entre grandes contratantes e mão de obra indocumentada e irregular não constitui novidade. Como já destacava Zolberg (1999) nas suas pesquisas sobre os mexicanos nos Estados Unidos, muitas vezes as autoridades envolvidas nesta problemática respondem a diversos interesses econômicos ${ }^{20}$. Isto significa que muitas vezes a contratação de trabalhadores indocumentados é possível pela omissão das autoridades, o que facilita a mão de obra barata e, na pior hipótese, de deportação do imigrante e de pagamento de punições econômicas, mas jamais de suspensão de atividades, situação que se repetiu com a assinatura do convênio por varejistas no ano 2007.

Como aspecto final a destacar, embora já mencionado, é o papel desempenhado pelos atores intermediários. Considerando os tipos de vínculos que as grandes firmas possuem com as oficinas de costura, os donos são agentes fundamentais na articulação destes interesses (lembrando que, em boa parte, tais patrões são eles próprios bolivianos). Parte de seu poder deriva do conhecimento dos riscos da condição de indocumentado. Os donos funcionam como o elemento de reprodução das relações econômicas entre as demandas das grandes firmas contratantes e, ao mesmo tempo, fornecem a logística para conseguir a mão-de-obra necessária, articulando-a desde a Bolívia. Se descobertos pelo Ministério de Trabalho e Emprego, suas oficinas são simplesmente fechadas e os imigrantes indocumentados, deportados. Reestruturar-se, depois, é só questão de prazo.

\footnotetext{
20 "The starting point for theorizing about migration policies is an understanding that they enter into play not merely as "error factors" in an equation whose parameters are social and economic, but as constitutive elements of international migration as a distinctive social phenomenon [...] As executors of policies, states do not function as autonomous actors, but rather as instruments manipulated by internal actors who have gained the upper hand in a particular sphere at a given time" (ZOLBERG, 1999, 81-82)
} 


\section{Conclusões}

Neste artigo, procurou-se expor a problemática da contratação de imigrantes bolivianos indocumentados em oficinas clandestinas de confecção e vestuário em São Paulo. A contribuição foi utilizar a perspectiva das cadeias globais como uma nova estratégia de análise para compreender as condições e consequências desse fluxo migratório para São Paulo. A utilização de uma perspectiva como as cadeias globais permitiu visualizar as complexas articulações que tornam possível a inserção econômica destes imigrantes bolivianos no nicho da confecção e do vestuário. Para fechar este trabalho, seria interessante retomar a pergunta inicialmente colocada: se as oficinas clandestinas se regularizarem, poderão continuar sendo competitivas? Esta pergunta consegue resumir todas as dimensões conflitantes neste vasto tema. Por uma parte dos dados analisados, pode-se deduzir que enquanto a indústria do vestuário no Brasil enfrentar importações altamente competitivas não será possível promover uma regularização destes trabalhadores indocumentados. Pela vulnerabilidade de sua condição, eles representam lucros para os donos de oficinas e para as grandes firmas que os contratam. E este é o resultado de um processo de ajuste à concorrência de outros países exportadores de vestuário e têxteis e de reestruturação econômica e de regimes de produção, o que permitiu a sua inserção neste determinado nicho econômico.

Perante este panorama econômico pouco animador, podemos reconhecer a escassa eficácia do exercício da governança local, a partir dos convênios e programas realizados por parte do Ministério de Trabalho e Emprego ao longo dos anos 2000. Foi possível observar que a partir da maior presença desta problemática na esfera pública, diversas tentativas por parte das instituições locais, estaduais e nacionais foram realizadas sem conseguir melhorar a situação do migrante.

Nesta enorme articulação de atores econômicos e de diferentes níveis, os atores intermediários são talvez o aspecto mais peculiar - os próprios imigrantes bolivianos que se tornaram empreendedores próprios e proprietários de oficinas -, valendo-se de sua própria experiência para efeito de recrutamento, logística, transporte e fornecimento de mão-de-obra. A configuração econômica, social e histórica deste nicho funciona em favor 
da reprodução das relações de superioridade, subordinação e condicionamento dos diversos atores nela envolvidos.

Como corolário, dever-se-ia repetir a pergunta sobre as reais possibilidades de as oficinas (e seus trabalhadores), uma vez regularizadas, continuarem sendo competitivas. Será possível pensar novas formas de configuração econômica e de inserção laboral de pessoas com as características dos imigrantes bolivianos (e, eventualmente, paraguaios)? A imposição de um padrão mundial de competitividade - importações a baixo custo poucas oportunidades parece permitir fora dos circuitos de subcontratação e exploração da mão de obra.

\section{Referências}

AGERGAARD, Jytte; FOLDS, Niels; GOUGH, Katherine. Global-local interactions: socioeconomic and spatial dynamics in Vietnam's coffee frontier. The geographical journal. v. 175, n. 2, jun. p. 133-145, 2009.

ARANGO, Joaquín. La explicación teórica de las migraciones: luz y sombra. Migración y Desarrollo. Zacatecas, Latinoamericanistas: Red Internacional de Migración y Desarrollo, n.1. , out. 2003. Disponível em:

<http://pendientedemigracion.ucm.es/info/gemi/descargas/articulos/42ARANGO_La_Expli cacion_Teorica_Migraciones_Luces_Sombras.pdf>. Acesso em: 12 fev. 2014.

BAENINGER, Rosana. Imigração boliviana em São Paulo. Nepo. Unicamp. São Paulo. 2013

BAIR, Jennifer. Global capitalism and commodity chains: looking back, going forward. Competition \& Change. v.l, n. 2, 9. p. 153-180, jun. 2005.

BRAGA MARTES, Ana Cristina. Gestión pública de la inmigración en Brasil. Migración y políticas sociales en América Latina. Rio de Janeiro: Konrad Adenauer Stiftung. , 2009. p. 59-79.

BRASIL. Ministério de Trabalho e Emprego em São Paulo. Pacto contra a precarização e pelo emprego e trabalho decentes em São Paulo: cadeia produtiva das confecções. São Paulo, 2009. Disponível em:

<http://www.justica.sp.gov.br/downloads/biblioteca/Pacto\%20da\%20ind\%C3\%BAstria\%20t\% C3\%AAxtil\%20contra\%200\%20trabalho\%20escravo\%20em\%20S\%C3\%A30\%20Paulo.pdf>. Acesso em: 12 fev. 2014. 
CASTLES, Steven; MILLER, Mark. La era de la migración movimientos internacionales de población en el mundo moderno. México: Colección América Latina y el Nuevo Orden Mundial, 2004.

CHANG WALDMANT, Tatiana. Entraves ao acesso à educação escolar de imigrantes indocumentados no Brasil sob a vigência do Estatuto do Estrangeiro: um debate necessário. ACTA CIENTÍFICA XXIX Congreso de la Asociación Latinoamericana de Sociología 2013. ISBN 978-956-19-0828-4. Disponível em: <http://actacientifica.servicioit.cl/biblioteca/gt/GT9/GT9_WaldmanT.pdf>. Acesso em: 12 fev. 2014.

COMERLATTO, Lairton; LINS, Hoyedo. Produção moveleira em São Bento do Sul (SC): a perspectiva das cadeias mercantis globais. Ensaios FEE. v. 29, n. 2, 2008. Disponível em: <http://revistas.fee.tche.br/index.php/ensaios/article/view/2186>. Acesso em: 12 fev. 2014.

DESENVOLVIMENTO urbano. Dobra o número de migrantes internacionais em São Paulo na última década. Informes Urbanos. São Paulo: Prefeitura de São Paulo, n. 15, dez. 2012. Disponível em: <http://smdu.prefeitura.sp.gov.br/informes_urbanos/pdf/27.pdf $>$. Acesso em: 12 fev. 2014.

FREITAS, Patrícia Tavares de Imigração boliviana para São Paulo e setor de confecção em busca de um paradigma analítico alternativo. In: BAENINGER, Rosana (Org.). Imigração boliviana no Brasil. Campinas: UNICAP. Núcleo de Estudos de População (Nepo): FAPESP: CNPq: Unfpa, 2013. p. 155-178.

FREITAS, Patrícia Tavares de Imigração e experiência social: o circuito de subcontratação transnacional de força-de-trabalho boliviana para o abastecimento de oficinas de costura na cidade de São Paulo. 2009. 00 f. Dissertação (Mestrado em....) - Departamento de Sociologia do Instituto de Filosofia e Ciências Humanas da Universidade Estadual de Campinas, Campinas. 2009

GEREFFI, Gary. Las cadenas productivas como marco analítico para la globalización. Problemas del Desarrollo, v. 32, n. 125, p. 9-3, abr./jun. 2001.

LINS, Hoyêdo. Dinâmicas planetárias e efeitos locais: a ótica das cadeias mercantis. Revista Sociedade Brasileira de Economia Política. Rio de Janeiro. n. 2, dez. p. 84-111, 2007.

MELO, Rosiane; CAMPINAS, Lúcia. Multiculturalidade e morbidade referida por imigrantes bolivianos na Estratégia Saúde da Família. In: O mundo da saúde. São Paulo. v.34, n.1, p. 25-35, 2010. Disponível em: <http://www.saocamilosp.br/pdf/mundo_saude/74/03_original_multiculturalidade.pdf >. Acesso em: 12 fev. 2014 .

SAYAD, Abdelmalek. A imigração ou os paradoxos da alteridade. São Paulo: Editora da USP, 1998. 
SILVA, Cristina da. Território, fronteiras e interações espaciais: os migrantes bolivianos em São Paulo. Revista Geonorte. Edição especial 3- III SIMPÓSIO NACIONAL DE GEOGRAFIA POLÍTICA. v. 7, n. 1, p.1.305-1.321, 2013.

SILVA, Sydney. Bolivianos em São Paulo: entre o sonho e a realidade. Estudos Avançados, n. 20, p. 157-170, 2006.

SOUCHAD, Sylvain. Souchad, S (2010) A imigração boliviana em São Paulo. Deslocamentos e reconstruções da experiência migrante. Institut de recherche pour le développement. Disponível em: <http://hal.ird.fr/ird-00486059/fr/>. Acesso em Jun. de 2014

- A confecção: nicho étnico ou nicho econômico para a imigração latino-americana em São Paulo? In: BAENINGER, Rosana (Org.). Imigração boliviana no Brasil. Campinas: UNICAP. Núcleo de Estudos de População (Nepo): FAPESP: CNPq : Unfpa, 2013. p. 75-92.

ZOLBERG, Aristide. R. Matter of State: theorizing immigration Policy. In: HIRSCHMAN, C, KASINITZ, P. and DEWIND, J. (Editors). The Handbook of international migration: the American experience. New York, Russell Sage Foundation. 1999. p. 71-93. 
A multidimensionalidade da imigração boliviana em São Paulo: perspectivas das cadeias globais como

Recebido em: 09/03/2014

Aprovado em: 15/05/2014

Universidade do Estado de Santa Catarina - UDESC

Centro de Ciências Humanas e da Educação - FAED

Revista PerCursos

Volume 15 - Número 28 - Ano 2014

revistapercursos@gmail.com 